\title{
The Traditional Craft of Dong People's Wind and Rain Bridge and Its Cultural Aesthetic Implication
}

\author{
Qianwei Jin \\ Postdoctoral Research Station \\ College of Liberal Arts \\ Hunan Normal University \\ Changsha, China 410081 \\ School of Arts and Culture \\ Guangxi University of Science and Technology \\ Liuzhou, China 545006
}

\begin{abstract}
The traditional craft appearance of Dong people's Wind and Rain Bridge architecture gives a sense of the distinctive characteristics, integrating bridge, corridor and pavilion, in whole wood structure, which is derived from the integration of the northern and southern traditional construction technologies, embodying the cultural inheritance and innovation consciousness faced by cultural diversity, greatly adapted to the geographical environment in which Dong ethnic groups live near the mountain and by the river, reposing Dong compatriots' geomantic protection concept, soul immortality, love and happiness, and other cultural aesthetic meaning.
\end{abstract}

Keywords-Dong people's Wind and Rain Bridge; traditional craft; cultural concept

\section{INTRODUCTION}

Dong people are mainly distributed in Southeast Guizhou Miao and Dong Autonomous Prefecture in Guizhou Province, Huaihua region in Hunan Province, Sanjiang, Longsheng and Rongshui in Guangxi Zhuang Autonomous Region, and remain about 330 Wind and Rain Bridges with distinctive ethnic characteristics, usually the bridge, corridor and pavilion are connected, and the entirety is whole wood structure, integrating convenient traffic, shelter from wind and rain, faith sustenance, and appreciation aesthetics. With the expansion of tourism communication, people usually vividly call them Wind and Rain Bridges, and the viewers are overwhelmed with the traditional technology of the architecture. Compared to other local communities which have no similar buildings, it becomes particularly unique, especially Guangxi Sanjiang Chengyang Wind and Rain Bridge enjoys the reputation as one of the world's four historical famous bridges, which makes it worth thinking about why the Dong people have such architecture technology, and what cultural connotation of the ethnic group is reposed.

\section{ANALYSIS ON TRADITIONAL CRAFTS OF WIND AND RAIN BRIDGE ARCHITECTURE}

Dong Wind and Rain Bridges adopt mortise and tenon joint, and stress that the whole wood structure does not use a single metal rivet, which is bridge, but also corridor and pavilion, both practical and aesthetic, and it's also a place for rest and sacrifice, whose building technology learns from traditional Northern and Southern technologies, and also adjusts measures to local conditions, creating art treasures in unique style.

\section{A. Geographic Features and the Structure of Wind and Rain Bridge}

According to the verification, the wooden covered bridge structure is mainly distributed from the longitude $108^{\circ}$ to $110^{\circ}$, latitude $25^{\circ}$ to latitude $31^{\circ}$, forming a covered bridge belt with clear outline, located 300 to 2000 meters above sea level. Mountains and rivers spread over this scope, therefore, paving road through mountains and building bridge across rivers can facilitate access to people, and such characteristics of the area can be said as roads bending with mountain, winding paths leading to secluded spots, and flying bridge crossing, sometimes there is mountain and river, with bridge and road, forming a unique southern scenery, road bridge can be seen everywhere in the area where the Dong live. The bridge is divided into the upper layer, the middle layer and lower layer. In the lower part, bridge pier is made of large bluestone, the six-faced cylinder reduces the resistance of water to maintain durability. The middle part is the bridge, whose structure is cantilever bracket, all made of wood. The upper layer is a pavilion spanning about 10 meters, made of traditional mortise and tenon joint beam column into a whole, between the pavilions there are seats and railings. Color patterns are painted on the beam and girder to add the beauty of the bridge. There is a shrine in the middle and on both sides of the bridge, to worship Guanyin, Laojun, Guan Yu and other gods. There is no fixed measure between the bridge deck and the pier, merely relying on the pier and frame to protect the long bridge forever. It should be noted that it is now known as Wind and Rain Bridge because the bridge railings extend outward to shelter wind and rain, both with special beauty and practical value, giving the viewers a deep impression. It can be found that the bridge building technology integrates the north and south, in which the full wooden tenon technology is a traditional skill of the north and south of our country, the gods worshiped on the bridge is also the product of multi-ethnic beliefs, and Dong villages surrounded by mountain and river 
present the ethnic characteristic architectural culture with such Wind and Rain Bridges.

\section{B. Ethnic Culture Inheritance and Innovation}

In the above-mentioned covered bridge belt, there are also people of other ethnic groups living, so why is Dong's building so distinctive? For example, why isn't there such building of Shui, Yao, Miao, etc. who also live in Sanjiang, Guangxi? Is it invented by Dong people themselves? Only the full wood structure without a single metal nail is enough to explain that it's not unique to the South, for the North also has such a technology, which is famous for large-scale palace buildings. Compared to the South which is famous for civil construction, the North reflects more official temperament, for example, the well-known Forbidden City and Confucius Hall are both tenon buttoned with totally natural craft, the reason here is easy to think of, for early people made a living by fishing, and the simple tools were mostly made of stone or wood. Therefore, in a very long time, they explored the full wood construction technology, while the metal products came from the technology of smelting later invented. In comparison, wood was easier to access, while the metal was valuable, which could not be afforded by ordinary people, therefore, the wooden structure was preferred in construction of buildings and houses, although the iron tools later slowly became daily items, especially that nails were not expensive, the use of nails did not mean solid joint, which is also easy to rust and be destroyed over a long time, however, the full wood tenon joint is easier to make the building seamless, durable, of course, the Dong people also carried out the transformation and innovation in the acceptance of foreign cultural impact, and combined with the living environment, not only inherited the wooden structure skills, but also injected the aesthetic principle of suspension balance, added aesthetic element according to the culture of the group, and made Wind and Rain Bridge strong and durable, with beautiful appearance, integrating convenient traffic, rest and recreation, sacrifice an faith.

\section{Cultural Diversity and Han Building Integration}

The building technology of covered bridge was spread from north to south. It is generally believed that after the Northern Song Dynasty perished, a large number of craftsmen moved southward to avoid the war, and the construction technology they took there was combined with the Southern technology, which, according to the rainy weather conditions in the south, enriched the function of sheltering wind and rain of the bridge, not only paying attention to practical, but also stressing sense of beauty, especially the roof tiles extended and became tilted shelter, which is the integrated product of Han culture and Dong culture, and can be described as the integration of Han and ethnic cultures, "Dong culture and Han culture have been inseparable in the history" [1] The gods worshiped on the bridge were mostly gods of the Central Plains region, such as the Guanyin Bodhisattva in Buddhism, Laojun in Taoism, and guardian god Guan $\mathrm{Yu}$, etc., showing the architectural characteristics of cultural diversity. Dong is generally considered to come from "Jiangxi" and "Wuzhou", as for the direction of its source, it's considered to be from east to west in Lingnan area, and in the migration process they naturally learned and integrated different cultures, now the collectively named Wind and Rain Bridge is a architectural boutique created by multi-ethnic culture. In addition, the Dong lived near mountains and rivers, and need to build roads bridge, so saving costs is also one of the factors to be considered, there is mostly stone and dense trees in mountains, so using local materials is totally possible. Good stone is selected to build the pier, and slender mountain wood is used as bridge material, which not only saves costs, but also enables ordinary people to afford it, because the money to build bridge shall be shared by all families to ultimately gather the village manpower and material resources to achieve the purpose of paving road and building bridge, because as long as they work, they can exploit stone, cut wood, and they refuse metal tools, which facilitates construction. According to practical experience, the traditional full-wood structure bridge technology is more solid and durable, and Dong's Wind and Rain Bridge is the innovative building integration process of Dong ethnic group after learning foreign culture.

\section{The Wind AND RAIN BRIDGE AND DONG CUlturAL CONCEPT}

Studies have found that now collectively named Wind and Rain Bridge is actually a cultural misreading, the bridge built by the Dong is called "wucjiu" in Dong language, which shall be translated into "Blessing Bridge" in Chinese. This title is very appropriate, because it represents Dong's cultural concept, while the Wind and Rain Bridge is named by outsiders based on the image. Because of the cultural transmission, people generally have accepted the name of the Wind and Rain Bridge, but for the Dong's cultural aesthetic implication of building bridges, calling Blessing Bridge is more appropriate.

\section{A. The Geomancy Protection Concept}

The essence of life is to solve the problem of food and clothing, and most ordinary people not only require personal safety, but also need to protect secure life, so making money becomes a universal appeal, which is reflected as protecting the money from leaking in geomancy. The bridges built by the Dong generally have the following purposes: one is for connection of mountains and rivers, because people can not go through valleys or rivers, and bridges have to be built to facilitate the tribe life; the second is to facilitate travel, also to protect geomancy, for Dong people believe that protecting geomancy is to ensure secure village and rich life, because bridges make the place a happy home; the third is purely to protect geomancy, because it's found in studies that bridge is not needed in some places for it's dry road, and there is no need to build a bridge according to terrain. So why do people still build a bridge? It's because that the bridge built blocks the outside insecurity, and ensures that the village wealth will not leak. There is another situation, the transformation of geomancy, because Dong ethnic group believes that life guarantee requires living near the mountain and by the river and adequate raw material, if the mountain trend is not ideal, or there is a terrain problem, a bridge is needed for transformation. There is a small village of less than 100 people in Sanjiang, Guangxi, where four bridges are built. One of them flushes with the hill, because the old people in the village believe that the hill is a tiger-head hill, and there a stone pig in 
the river, for fear of fight between tiger and pig, this bridge is used to protect the village to enjoy a quiet life, and they do not want to be damaged by insecurity factors; another is to block the geomancy, so that the village wealth is blocked to ensure that income increase every year, of course, other bridges may be built really for access convenience, therefore, bridge means protection to the Dong, which is a blessing bright to protect the villagers' wealthy and safe life.

\section{B. The Concept of Soul Immortality}

The large number of Dong bridge and the ingenious craftsmanship are praised by outsiders, which also makes people think whether it's only because the Dong people like to build bridges, and whether there is deep reason. It should be linked to the Dong's concept of soul immortality and bridge function, because Dong ethnic group believe that the soul of people is immortal, only the body die, and such situation is the separation of yin and yang, and the so-called statement of dead people living in the underworld while the living people live in the world. The physical death requires soul assumption for reincarnation through a bridge. The soul of the dead people can walk to the underworld for reincarnation, so the bridge is very important, which is necessary for soul immortality and reincarnation. The Dong people are willing to build bridges to provide protection for the soul immortality. The living people's soul and body are integrated, but the human soul may also be lost, and then they get sick, so the wooden bridge can become the home of soul, therefore, Dong people build bridge extremely carefully, for every board may be reposed the soul of a different clansman, even the soul of ancestors. If the whole village relocates due to war or famine, they will also move the important bridges, in fact, it is to protect the soul of ancestors and future generations from getting lost. Embodied in daily life, Dong people are eager to build bridge, "the rich people donate 200,300 or 100 yuan, while the poor ones donate tens of yuan. Poorness or richness do not matter in material supply, the work time is not calculated, all the people just do their best." It is because the bridge is equivalent to the soul of people with a special significance, that on June 21, 1982, when flood flushed Chengyang Bridge, the local Dong people struggled to rescue it, "they care it so much as it was their life. " [2] The reason is that the bridge is the bridge of life, and the coffin of dead people shall also go through the wooden bridge, meaning going into the underworld across the wooden bridge, and can reincarnate to the world. The soul of human is immortal, and the wooden bridge becomes the intermediary for life and death transformation, reposed with the Dong ethnic group's special cultural ideas.

\section{The Concept of Love and Happiness}

Love seems to be patent for minorities. Compared to the Han in Central Plains, it can be said that, during the feudal dynasties, due to the rigid Neo-Confucianism dogma, young men and women of Han during Ming and Qing Dynasties were generally subject to parents and matchmakers for marriage, and they seemed to forget love. In such context, the young men and women of minorities took chances of assembly, singing and dance to create the happiness basis for marriage and love, so their love and marriage pay more attention to emotional exchanges. Dong bridges are also related to love. It is said that there is a demon in the river, who appropriates beautiful girls in the village to itself. Once, a beautiful new wife in the village was swept away by the demon, and her husband was so despair that he went to the river, preparing for suicide, and dragon in the river knew the cause of the matter, who was not only sympathetic to the encounter of the Dong ethnic group, but also struggled to fight with the demons, and ultimately killed it and rescued the new wife, protecting the safety of villagers. Of course, it also ensured that young men and women safely enjoy the sweet love and marriage. People built a bridge with the dragon's image painted on it to commemorate the flower dragon, and they also burned incense to show their appreciation in the dragon for enabling people to have a sweet life, therefore, Dong bridge is also a wonderful place for young men and women to get together. They may sing together in sunny days or night with moonlight, to create a romantic atmosphere, to prepare for the formation of a happy marriage and family, it can be said, Dong bridges' wonderful structure and beautiful scenery make a great place, and young men and women can fall in love here in a warm and wonderful environment. It is also a sacred ritual place, where the gods bless holy divine love, therefore, Dong bridges bless love of young men and women, and convey the cultural value of pursuing sweet love and happy marriage.

\section{CONCLUSION}

Dong ethnic's traditional construction technology is vividly manifested in the Wind and Rain Bridge praised by people, which is an integration of the northern and southern building culture, with the building wisdom of heritage and innovation, reflecting the aspiration of harmony between man and nature, containing the unique ethnic cultural belief. It's called blessing bridge in Dong language, reposed with the special aesthetic meaning of geomancy protection, soul immortality, love and happiness.

\section{REFERENCES}

[1] Liu Hongbo. The construction ceremony of Dong's Wind and Rain Bridge - Taking the construction of Longji Wind and Rain Bridge in Sanjiang Dong's Autonomous County, Guangxi [J]. Journal of Culture, 2016 (1): 177.

[2] Zhang Zezhong. Dong's Wind and Rain Bridge [M]. Beijing: Huaxia Culture and Arts Publishing House, 2001: 3. 